\title{
The falling twin rate in Greece
}

\author{
VASSILIOS KATSOUYIANNOPOULOS \\ From the Department of Hygiene, University of Ioannina Medical School, Ioannina, Greece
}

SUMMARY A significant fall of 33\% has occurred in the incidence of twins in Greece over the past 45 years. In 1933-5 the twinning rate in the whole country was $14 \cdot 3$ per 1000 ; in $1974-6$ it was 9.6 per 1000. The decline was smaller in Greater Athens than in rural and urban areas outside the city. Changes in the fertility behaviour of the women of Greece, a reduction in parity, and the shorter reproductive life of mothers, were the main reasons for the decline in the incidence of twins. The pattern of change has been different in the rural and urban populations outside Athens, which explains the steeper decline in the twinning rate in those areas.

Over the past 40 years a gradual fall in the ratio of twins to total maternities has been reported from many countries. Guttmacher ${ }^{1}$ observed a decline of $8 \%$ in the incidence of twins over a 12-year period in the United States of America; as others ${ }^{2}$ have shown, most of the decline occurred in the period 1936-43, but the incidence of twins in the USA has continued to show a further downward trend. ${ }^{34}$ In England and Wales the twinning rate has shown a slight but steady fall, ${ }^{5}$ and this has also happened in Scotland. ${ }^{6}$ From Hungary there has been a report of a decrease in twin births, ${ }^{7}$ and similar reports have come from many other countries all over the world. ${ }^{8}$ Elwood ${ }^{9}$ showed that in Canada there was a fall of $20 \%$ in the crude twin rate between 1926 and 1970. In Ireland also the rate is now lower than in the past. ${ }^{10}$

The changes mentioned above were attributed mainly to the decline of the dizygotic twinning rate.

Twin incidence is also declining in Greece.

CHANGES IN THE CRUDE TWINNING RATE Table 1 summarises data on total and twin maternities in Greece during the last 45 years, taken from the Vital Statistical Service of Greece (NSSG). ${ }^{11}$ The data include both live born and stillborn infants. The Table shows a steady fall in twin incidence. The fall between 1933-5 and 1974-6 was $33 \%$, a remarkable drop in the rather short period of 45 years. The decline was steeper in the second 20 -year period, $1956-76$. The twinning rate was $14 \cdot 3$ per 1000 in $1933-5$ and fell to 12.6 per 1000 in $1956-8$, a decline of $12 \%$. Between $1956-8$ and 1974-6, the rate dropped from 12.6 per 1000 to 9.6

Table 1 Crude twinning rate in Greece, 1933-76

\begin{tabular}{|c|c|c|c|}
\hline \multirow[b]{2}{*}{ Years } & \multicolumn{2}{|c|}{ Maternities } & \multirow{2}{*}{$\begin{array}{l}\text { Twinning } \\
\text { rate }\end{array}$} \\
\hline & Total & Twin & \\
\hline $\begin{array}{l}1933-5 \\
1956-8 \\
1965-7 \\
1974-6\end{array}$ & $\begin{array}{l}588316 \\
469318 \\
470396 \\
433820\end{array}$ & $\begin{array}{l}8432 \\
5906 \\
5405 \\
4167\end{array}$ & $\begin{array}{r}14 \cdot 33 \\
12.58 \\
11.49 \\
9.60\end{array}$ \\
\hline
\end{tabular}

per $1000-a$ a $24 \%$ decrease. This downward trend continued in 1977 , when total maternities registered were 143955 , twin pairs 1257, and the twinning rate was nine per 1000 .

INCIDENCE IN URBAN AND RURAL POPULATIONS Table 2 shows that rates are higher in rural areas, lower in Athens, and intermediate in the rest of the country. This is consistent in all years during the 1960 s and 1970 s for which data are available. A small discrepancy was observed in the period 1956-8, when the twin rate was a little higher in the rest of the country than in rural areas.

Twin frequency remained almost static in Athens between 1956 and 1967, fluctuating around 10 sets of twins per 1000 total maternities (Table 2). From 1968 it showed a small decrease, and fell finally to 9.07 per 1000 in $1974-6$, a fall of $9 \%$.

In rural areas the twinning rate was 12.9 per 1000 in $1956-8$ and declined slowly to 12.7 per 1000 at the end of the first decade (Table 2). It continued to decline faster between 1967 and 1976 and reached a level of 10.3 twins per 1000 total maternities in the period 1974-6, so the total decrease was equal to $20 \%$.

In the rest of the country, semiurban and urban areas outside Athens, the fall in the rate was even more remarkable: $29 \%$ between 1956-8 and 1974-6. At the end of the 21-year period 1956-76, the three

Table 2 Twinning rates by region in Greece, 1956-76

\begin{tabular}{|c|c|c|c|c|}
\hline \multirow[b]{2}{*}{ Region } & \multirow[b]{2}{*}{ Years } & \multicolumn{2}{|c|}{ Maternities } & \multirow{2}{*}{$\begin{array}{l}\text { Twinning } \\
\text { rate }\end{array}$} \\
\hline & & Total & Twin & \\
\hline Athens & $\begin{array}{l}1956-8 \\
1965-7 \\
1974-6\end{array}$ & $\begin{array}{r}80149 \\
119443 \\
143606\end{array}$ & $\begin{array}{r}798 \\
1204 \\
1303\end{array}$ & $\begin{array}{r}9.95 \\
10.08 \\
9.07\end{array}$ \\
\hline Rural areas & $\begin{array}{l}1956-8 \\
1965-7 \\
1974-6\end{array}$ & $\begin{array}{l}240482 \\
185301 \\
123197\end{array}$ & $\begin{array}{l}3105 \\
2352 \\
1272\end{array}$ & $\begin{array}{l}12.91 \\
12.69 \\
10 \cdot 32\end{array}$ \\
\hline $\begin{array}{l}\text { Rest of the } \\
\text { country }\end{array}$ & $\begin{array}{l}1956-8 \\
1965-7 \\
1974-6\end{array}$ & $\begin{array}{l}148687 \\
165652 \\
167017\end{array}$ & $\begin{array}{l}2003 \\
1849 \\
1592\end{array}$ & $\begin{array}{r}13 \cdot 47 \\
11 \cdot 16 \\
9 \cdot 53\end{array}$ \\
\hline
\end{tabular}


populations all had lower twinning rates and were closer to each other than at the beginning of the period, but the rural population still showed the highest crude rate.

\section{Discussion}

The NSSG ${ }^{11}$ unfortunately does not publish figures on twin births by sex and by maternal age and parity. So it was not possible to calculate the dizygotic and monozygotic twinning rates according to the age and parity of the mother. Thus, the possible explanations offered here for the declining twin rate in Greece are indirect and based on the changes in the fertility behaviour of the general population.

It has been known since $1865^{12}$ that maternal age and parity account for the greatest variance in twinning rate. Therefore, any changes in the fertility patterns of a population would influence the twin incidence. Reduction of parity from five children on average per family to three, and a shorter reproductive life of mothers, from 15-50 to 15-30 years of age, would cause a lower twinning rate.

The birth rate in Greece has been falling. ${ }^{13}$ In 1934 the crude birth rate was 31 per 1000, in 1956 it was 20 per 1000 , and in 1976 it was 16 per 1000 . In about 40 years the crude birth rate has fallen by about $50 \%$.

Both total and twin maternities decreased successively in Greece (Table 1). Births in Athens have almost doubled, while the opposite has happened in rural areas, as a result of an enormous internal migration into the capital (Table 2). But these changes do not fully explain the proportionately greater decline of twin incidence in the whole country and in various regions.

The fall in the fertility of the Greek population is due mainly to birth control and family planning. ${ }^{13}$ The principal effects of these changes have been firstly, a substantial increase in the percentage of mothers of lower parity and, secondly, a steady decrease in the percentage of births to mothers aged 30 and over. Pregnancies after the age of 35 and more than three children per family are exceptional nowadays in Greece. ${ }^{13}$ But conceiving children at ages 35-40 when gonadotropin release from the pituitary is unusual, and high parity, are the two main factors connected with higher dizygotic twin incidence. ${ }^{14-16}$ Thus it may be suggested that reduced parity acted upon the dizygotic twin rate, exactly as it did in other countries.

The observed differentials in the age-specific and parity-specific fertility rates were more impressive in rural areas and in the rest of the country than in
Athens, which accounts for the faster decline in twin incidence in the Greek population outside Athens. In 1974-6 the proportion of births of higher parity and to older mothers remained higher in the rural population than in the population of Athens and in the rest of the country. There could be many explanations for this, including tradition, religion, and educational and socioeconomic status.

Since the demographic shift of the age-specific and parity-specific fertility rates is still continuing in Greece, ${ }^{13}$ a further fall in the twinning rate can be expected.

Reprints from Dr. V. Katsouyiannopoulos, Department of Hygiene, University of Ioannina Medical School, Ioannina, Greece.

\section{References}

${ }^{1}$ Guttmacher AF. The incidence of multiple births in man and some of the other unipara. Obstet Gynecol 1953; 2: 22-35.

${ }^{2}$ Jeanneret $O$, MacMahon B. Secular changes in rates of multiple births in the United States. Am J Hum Genet 1962; 14: 410-25.

${ }^{3}$ Allen G, Schachter J. Do conception delays explain some changes in twinning rates? Acta Genet Med Gemellol 1970; 19: 30-4.

${ }^{4}$ Wyshak G. Some observations on the decline in the United States dizygotic twinning rate. Soc Biol 1975; 22: 167-72.

${ }^{5}$ Registrar General. Statistical Review for 1966. London: HMSO: 36-48.

${ }^{6}$ MacGillivray I. Changing incidence of twinning in Scotland in 1939-68. Acta Genet Med Gemellol 1970; 19: 26-9.

${ }^{7}$ Czeizel A, Acsadi G. Demographic characteristic of multiple births in Hungary. Acta Genet Med Gemellol 1971; 20: 301-13.

James WH. Secular changes in dizygotic twinning rates. $J$ Biosoc Sci 1972; 4: 427-34.

${ }^{\circ}$ Elwood JM. Changes in the twinning rate in Canada 1926-70, Br J Prev Soc Med 1973; 27: 236-41.

${ }^{10}$ Dean G, Keane T. An investigation of the high twinning rate in the Republic of Ireland. Br J Prev Soc Med 1972; 26: 186-92.

${ }^{11}$ Vital Statistical Service of Greece (NSSG). Vital Statistics of Greek population 1956-77. NSSG: Athens.

${ }^{12}$ Duncan M. On some laws of the production of twins. Edinburgh Med J 1865; 10: 767-81.

${ }^{13}$ Katsouyiannopoulos V. Ageing components of Greek population. In: Proceedings of the Sixth Greek Medical Congress, Athens, 1980 (in press).

14 Yerushalmy $J$ and Sheerar, S.E. Studies on twins. The relation of order of birth and age of parents to the frequency of like-sexed and unlike-sexed twin detiveries. Hum Biol 1940; 12: 95-113.

${ }^{15}$ Waterhouse JAH. Twinning in twin pedigrees. Br J Prev Soc Med 1950; 4: 197-216.

${ }^{16}$ Bulmer MG. The Biology of twinning in man. Oxford: Clarendon Press, 1970. 